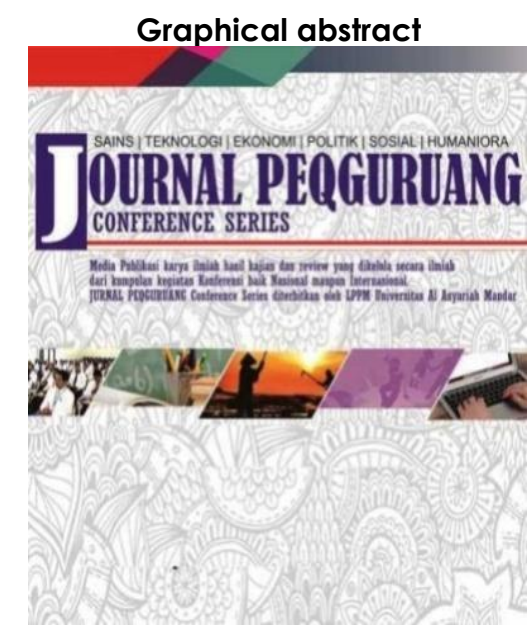

\title{
HUBUNGAN TINGKAT PEMAHAMAN DAN PARTISIPASI MASYARAKAT DUSUN SILOPO TERHADAP PENERIMA BANTUAN IURAN BPJS KESEHATAN
}

${ }^{1 *}$ Muh. Said Mukharrim, ${ }^{2}$ Urwatil Wusqa Abidin, ${ }^{3}$ Fika Ayu Rahmani

*Kesehatan Masyarakat Fakultas Kesehatan Masyarakat Universitas Al Asyariah Mandar

Corresponding author

saidmukharrim@gmail.com

\begin{abstract}
Be that as it may, truth be told, BPJS members who have enlisted in Silopo Hamlet are as yet numerous who have not utilized BPJS Kesehatan in Silopo Hamlet from 903 who use BPJS Kesehatan numbering 400 individuals and who use BPJS Wellbeing PBI upwards of 100 individuals. This exploration means to discover the connection between Training, Business, Pay, Support, and Comprehension with BPJS Wellbeing Commitment Help Beneficiaries. This kind of examination is quantitative exploration with an insightful study approach utilizing Cross Sectional plan. The populace in this examination is upwards of 400 Bpjs Wellbeing Members. The examining strategy utilized in the investigation was unplanned inspecting, acquired by 99 individuals. The information investigation performed is a univariate and bivariate examination with the Chi Square test. The outcomes showed that there is a connection between the factors of Training, work, pay, interest with the degree of comprehension of PBI BPJS Wellbeing with a worth of Chi Square $p=0.000$ and a resistance standard of 0.005 , Understanding variable relationship with PBI BPJS Wellbeing with Chi Square worth $p=0.000$ and resilience standard 0.005. Guidance to BPJS Kesehatan to keep on giving great wellbeing administrations and help the local area in gaining admittance to wellbeing administrations.

Keywords : BPJS, JKN, Membership, Understanding
\end{abstract}

\section{Abstrak}

Dalam realitasnya peserta BPJS yang telah terdaftar di Dusun Silopo masih banyak yang belum menggunakan BPJS Kesehatan di Dusun Silopo dari 903 yang menggunakan BPJS Kesehatan berjumlah 400 jiwa dan yang menggunakan PBI BPJS Kesehatan sebanyak 100 jiwa. Penelitian ini bertujuan untuk mengetahui hubungan antara Pendidikan, Pekerjaan, Pendapatan, Partisipasi, dan Pemahaman dengan Penerima Bantuan Iuran BPJS Kesehatan. Jenis penelitian ini ialah penelitian kuantitatif dengan pendekatan survey analitik menggunakan desain cross sectional. Total populasi dalam penelitian ini ialah 400 peserta BPJS Kesehatan. Teknik sampling yang digunakan dalam penelitian ini ialah Accidental Sampling, diperoleh sebanyak 99 orang. Analisis data dilakukan ialah univariat dan analisis bivariat dengan uji Chi Square. Hasil penelitian menunjukkan bahwa adanya hubungan antara variabel pekerjaan, pendapatan, partisipasi dengan tingkat pemahaman PBI BPJS Kesehatan dengan nilai Chi Square $p=0,000$ dan standar toleransi 0,05, Adanya hubungan variabel Pemahaman dengan PBI BPJS Kesehatan dengan nilai Chi Square $p=0,000$ dan standar toleransi 0,05. Saran kepada pihak BPJS Kesehatan agar tetap memberikan pelayanan kesehatan yang baik dan membantu masyarakat dalam mendapatkan akses pelayanan kesehatan. Kata kunci : BPJS, JKN Kepesertaan, Pemahaman

\section{Article history}

DOI: https://dx.doi.org/10.35329/jp.v3i2.2536

\begin{tabular}{l|l|l|l} 
Received : 01 & September 2021 & Received in revised form : 12 Oktober 2021 & Accepted : 14 November 2021
\end{tabular} 


\section{PENDAHULUAN}

Kesehatan ialah suatu kebutuhan mendasar bagi seseorang, kemudian sehat ialah hak bagi setiap warga negara yang dilindungi oleh Konstitusi. Setiap negara menyatakan bahwa kesehatan ialah modal besar agar bisa mencapai kesejahteraan. Oleh sebab itu, meningkatkan pelayanan kesehatan dasarnya ialah investasi sumber daya manusia untuk mencapai masyarakat yang sejahtera. (Syahrul, 2016)

Negara melalui pemerintah NKRI mempunyai keharusan untuk meningkatkan sistem asuransi sosial untuk memenuhi hak setiap orang atas asuransi sosial (Pasal 34 UUD 1945). Salah satu upaya pemerintah untuk memenuhi hak atas asuransi sosial ialah melalui Sistem Asuransi Sosial Nasional (SJSN). Jaminan Kesehatan Nasional (JKN) ialah asuransi sosial di bidang kesehatan bagi seluruh rakyat Indonesia yang ialah bagian dari SJSN. (Mardewi, 2019)

UU no. 24 Tahun 2011 menjelaskan bahwa JKN diselenggarakan oleh BPJS (Badan Penyelenggara Asuransi Sosial) dengan 2 program, yakni BPJS Kesehatan dan BPJS Ketenagakerjaan. Dalam melaksanakan program ini, BPJS bekerja sama dengan mitra untuk melaksanakan program menggunakan standar pelayanan yang ditetapkan oleh BPJS. Mitra dalam pelaksanaan BPJS ialah pelayanan kesehatan yang akan memberikan pelayanan kesehatan seperti rumah sakit, klinik medis dan praktek dokter. (Kemenkes, 2013)

Jenis keanggotaan BPJS sebenarnya dibagi menjadi beberapa kategori partisipasi, yakni peserta BPJS PBI (penerima bantuan iuran) dan Non PBI (nonpenerima bantuan iuran). ialah peserta BPJS yang kontribusi bulanan dibayar sendiri. (Marta, 2015)

peserta BPJS PBI dibagi lagi menjadi 2 kelompok, yakni peserta BPJS PBI APBD (sebelumnya pemegang kartu Jamkesda) yang kontribusi bulanan ditanggung oleh pemerintah daerah dan peserta BPJS PBI APBN (sebelumnya pemegang kartu Jamkesmas) yang kontribusinya bulanan ialah tanggung jawab pusat pemerintah.

Sementara itu, peserta BPJS Non-PBI dibagi lagi menjadi 2 kategori, yakni peserta BPJS Mandiri dan BPJS (PPU) pekerja yang penerima upah, peserta BPJS Mandiri dimaksudkan untuk non-pekerja (BP) dan pekerja non-upah (PBPU) sementara peserta BPJS PPU ditujukan untuk penerima upah atau pekerja yang bekerja di sebuah perusahaan, baik perusahaan pemerintah (PNS / TNI Polri) dan karyawan swasta. (Amin, 2020)

Berikut ini ialah perbedaan antara peserta BPJS PBI dan Non PBI:

Anggota BPJS PBI hanya untuk masyarakat miskin dan tertindas oleh informasi bantuan yang ramah, sedangkan peserta BPJS Non PBI ialah untuk penduduk yang mampu yang terdiri dari tenaga kerja bukan penerima upah (PBPU), non spesialis (BP misalnya, pemilik organisasi, dan sebagainya, dan selanjutnya pencari nafkah (PPU)

Peserta BPJS PBI hanya memenuhi syarat untuk bpjs kelas 3, sedangkan non-PBI memenuhi syarat untuk kelas 1, kelas 2 dan kelas 3. (baca: kontras di kantor bpjs kelas 1, 2 dan 3)

Anggota BPJS PBI hanya dapat mencari pengobatan di Puskesmas tingkat 1 di pusat kesehatan kecamatan atau kota, sedangkan peserta BPJS Non PBI dapat memilih kantor kesehatan yang belum benar-benar mapan dan telah bekerjasama dengan bpjs di wilayah tempat tinggalnya.

Anggota BPJS PBI memiliki biaya bulanan yang ditanggung oleh otoritas publik, kemudian tidak perlu membayar sendiri komitmennya, sedangkan BPJS non PBI anggota harus membayar biaya bulanan tanpa orang lain, meskipun bukan peserta BPJS dari pertemuan Spesialis yang mendapatkan kompensasi sampai batas tertentu ditanggung oleh organisasi.

Peserta BPJS PBI dan Non PBI yang mengambil kelas 3 tidak harus memiliki saldo keuangan, sedangkan peserta Non PBI gratis yang mengambil kelas 1 dan 2 harus memiliki buku besar saat mendaftar.

Untuk menjadi peserta BPJS PBI dan berhenti menjadi peserta BPJS PBI, harus disarankan dengan mengkompromikan informasi dari Layanan Silaturahmi berdasarkan referensi dari bantuan sosial lingkungan. daftarkan diri Anda baik melalui organisasi tempat Anda bekerja atau datang langsung ke kantor bpjs dengan asumsi Anda harus menjadi anggota gratis. (Jaya, 2017)

Update informasi anggota PBI ialah sebagai per Pengumuman dari dari Pendeta dari Get-kumpul Republik Indonesia Nomor 109 / HUK / 2019 tentang Perubahan Informasi Anggota Penerima Manfaat dari 2019 cakupan Kedelapan Tahap Medis Komitmen Bantuan.

BPJS Kesehatan mengeksekusi Pendeta Pengumuman Sosial dan memperbarui informasi anggota PBI. PBI pembaruan informasi anggota tidak akan mengubah 2019 informasi anggota APBN PBI. Jumlah sisa bagian 96.800.000 individu, termasuk perubahan atau substitusi untuk anggota ini dan terdaftar bayi anggota PBI. (KEMENSOS, 2018)

Pemda diharapkan memiliki pilihan untuk mengarahkan dan mengarahkan daerah setempat untuk mengecek status keikutsertaan PBI-nya dengan mendatangi Bansos atau Dinas Kesehatan Kabupaten/Kota terdekat, Kantor Kesejahteraan Sosial Tingkat I (FKTP), poliklinik PIPP, BPJS Tempat Pelayanan Kesehatan 1500 400, BPJS Kesejahteraan Klien Portabel Kesejahteraan, ke BPJS Kesejahteraan terdekat Kantor Pelayanan Kesejahteraan yang mendaftarkan PBI, BPJS Kesejahteraan yang memberikan sertifikasi, dan pemerintah terdekat yang berhubungan langsung dengan daerah setempat dalam memberikan penyelenggaraan kesejahteraan melalui dinas kesehatan di setiap kecamatan. 
Data dari Kabupaten Sulawesi Barat menggelar Rapat Koordinasi Kerja Sama Pelaksanaan Program PBI Tingkat Bersama Sulawesi Barat yang digelar di Hotel dMaleo Mamuju. Hadir dalam pembinaan ini Sekda Sulbar, Pengurus Komisi IV DPRD Sulbar, Pengurus Mamasa, Pejabat Ahli Majene, Sekda Provinsi Mamuju Utara, Mitra Mamuju, Fokal Mamuju dan Polewali Mandar, Pembina Tanggung Jawab Komisi Sistem DPRD Sulbar. Bantuan Pemerintah Daerah, Kepala Bidang Bantuan Pemerintah, Kepala Bidang Bantuan Sosial Pemerintah, dan beberapa SKPD terkait. Sekretaris Daerah Sulawesi Barat, Drs. Ismail Zainuddin, M.Pd dalam wacananya menyampaikan bahwa Pemda Sulbar fokus pada pengakuan Jauh jangkauan bantuan Pemerintah Inkorporasi sebelum tahun 2019.

Pasal 34 ayat 1 UU tersebut mengatur bahwa orang miskin dan anak yang diberhentikan ditanggung oleh Negara. Baik pemerintah pusat maupun pemerintah ekologi telah berupaya untuk menunjukkan tanggung jawab mereka. Penduduk yang ditanggung oleh Pemerintah Pusat (PBI) adalah 531.021 orang, penduduk yang terdaftar oleh pemerintah biasa adalah 208.128 Semua dari 555.889 orang yang tidak memiliki jaminan kesehatan yang layak untuk menjadi peserta JKN melalui PBI. oleh Pemerintah Daerah, yang didaftarkan oleh daerah usaha, didaftar secara bebas atau didaftarkan secara lengkap oleh pemerintah provinsi, hal ini sesuai dengan Pasal 6A Undang-Undang Nomor 111 Tahun 2013 tentang Perubahan Atas Undang-Undang Nomor 12 Tahun 2013 tentang Penyertaan Administrasi Kesejahteraan.

Informasi Perpres Polewali Mandar hingga Juni 2018, pencantuman mutlak kerjasama dalam program JKN-KIS di Rezim Polewali Mandar telah menghubungi 390.995 orang dari jumlah 516.537 penduduk Perda Polewali Mandar atau sudah mencapai 75,70\%. Artinya masih ada 125.542 penduduk atau $24,30 \%$ dari total penduduk Polewali Mandar.

Desa Mirring ialah desa yang sangat strategis dipandang dari sumber daya alam seperti perkebunan, pertanian dan wilayah laut yang membentang luas di sebelah selatan Desa yang sangat menunjang perekonomian masyarakat. Desa Mirring berjarak $\pm 22,572 \mathrm{M}$ dari pusat pemerintahan kabupaten dan $\pm 4,500 \mathrm{M}$ dari pusat pemerintahan kecamatan.

Jumlah penduduk Dusun Silopo \pm 903 jiwa yang terdiri Laki-laki \pm 320 jiwa, perempuan \pm 583 jiwa dan terdiri dari 201 KK. Tidak pernah bersekolah persentase $23 \%$, pernah sekolah SD tetapi tidak tamat $20 \%$, tamat SD/Sederajat 21\%, SLTP/Sederajat $22 \%$, SLTA/Sederajat 16\% dari data tersebut bisa kita lihat bahwa rendahnya pendidikan warga Kota Mirring kemudian mempengaruhi tingkat pemahaman masyarakat tentang pentingnya Proyek Kesejahteraan BPJS JKN dimana kelompok Masyarakat Kota Mirring umumnya tersebar di daerah pesisir dan lereng. Hal ini menyulitkan petugas BPJS Kesejahteraan selama ini untuk menyebarkan data BPJS Kesehatan, maka penduduk Desa Mirring yang memiliki BPJS Kesehatan 2.340 jiwa, sedangkan Dusun Silopo sebanyak 400 jiwa dan yang menggunakan PBI BPJS Kesehatan sebanyak 100 jiwa. (DINAS CAPIL , 2019)

Berdasarkan uraian diatas,maka dari itu peneliti tertarik untuk meneliti "Hubungan Tingkat Pemahaman dan Partisipasi Masyarakat Dusun Silopo terhadap Penerima Bantuan Iuran BPJS Kesehatan”

\section{METODE PENELITIAN}

Perspektif dari dasar masalah dalam pemeriksaan ini. Jenis pemeriksaan yang digunakan ialah eksplorasi kuantitatif dengan pendekatan investigasi cross sectional, khususnya faktor bebas dan lingkungan yang terlihat dalam rentang waktu yang sama sepenuhnya bertujuan untuk mengetahui hubungan antara tingkat pemahaman dan kerjasama kelompok masyarakat Dusun Silopo terhadap penerima Bantuan Komitmen BPJS Kesehatan. (Martono, 2011)

Penduduk yang diperiksa ialah seluruh pasal atau untuk keadaan ini orang yang sesuai dengan tujuan eksplorasi, dalam penelitian ini penduduk ialah 400 orang dari seluruh peserta BPJS Kesehatan yang terdaftar di ruang fungsi Binuang Wellbeing Center, Mirring Town, Silopo Dukuh.

Contohnya ialah artikel yang sedang diperiksa yang dianggap membahas seluruh penduduk eksplorasi (Lawrence Green 1991). Contoh dalam investigasi ini ialah sebagian anggota BPJS Kesejahteraan di Ruang Kerja Puskesmas Kelompok Masyarakat Binuang, Kota Mirring, Dusun Silopo.. (Sogiyono, 2017)

Contoh dalam investigasi ini juga melalui siklus penyaringan sesuai dengan standar contoh yang diperlukan untuk setiap pertanyaan dalam survei. Penjawab yang tidak memenuhi standar dilarang mengikuti uji eksplorasi. Tentang memutuskan tes dungan menggunakan resep slovin:

Keterangan:

$$
n=\frac{N}{1+N e^{2}}
$$

$\mathrm{N}=$ Besar Populasi Jumlah Populasi

$\mathrm{n}=$ Jumlah Sampel

$\mathrm{e}=$ Batas Toleransi Kesalahan (error toleransi 0,05)

$$
\begin{aligned}
n & =\frac{N}{1+(400 \times 0.0025)} \\
n & =\frac{400}{1+4.01} \\
n & =\frac{400}{4.01} \\
n & =100
\end{aligned}
$$




\section{HASIL DAN PEMBAHASAN}

\section{A. Analisis Univariat}

Penelitian tentang tingkat pemehaman masyarakat terhadap penerima bantuan iuaran BPJS kesehatan desa mirring yang dilakukan pada 100 sampel.

\section{Distribusi Frekuensi}

a. Pendidikan

Table 1

Distribusi Frekuensi Menurut Pendidikan

\begin{tabular}{ccc}
\hline Pendidikan & $\mathrm{n}$ & $(\%)$ \\
\hline Tidak sekolah & 10 & 10.0 \\
SD & 30 & 30.0 \\
SMP & 47 & 47.0 \\
SMA & 10 & 10.0 \\
SI & 3 & 3.0 \\
Total & 100 & 100.0 \\
\hline
\end{tabular}

Berdasarkan table 1 Distribusi pendidikan tidak sekolah sebanyak 10 penjawab (10.0) dan SD sebanyak 30 penjawab (30.0) pendidikan SMP sebanyak 47 penjawab (47.0) Pendidikan SMA sebanyak 10 penjawab (10.0) sedangkan Pendidikan SI sebanyak 3 penjawab (3.0).

\section{b. Jenis Kelamin}

Table 4.2

Distribusi Freukensi Berdasarkan Jenis Kelamin

\begin{tabular}{lll}
\hline Jenis Kelamin & $\mathrm{n}$ & Persentase (\%) \\
\hline Laki - laki & 70 & 70.0 \\
Perempuan & 30 & 30.0 \\
Total & 100 & 100.0 \\
\hline
\end{tabular}

Berdasarkan table 2 distribusi jenis kelamin laki-laki sebanyak 70 penjawab (70.0)dan jenis kelamin perempuan sebanyak 30 penjawab (30.0).

c. Pekerjaan

Table 4.3

Distribusi Freukensi Berdasarkan pekerjaan

\begin{tabular}{ccc}
\hline Pekerjaan & $\mathrm{N}$ & Persentase (\%) \\
\hline Petani & 1 & 21.0 \\
Nelayan & 55 & 55.0 \\
PNS & 3 & 3.0 \\
TNI/POLRI & 1 & 1.0 \\
Wiraswasta & 20 & 20.0 \\
Total & 100 & 100.0
\end{tabular}

Berdasarkan table 4.3 distribusi pekerjaan petani sebanyak 21 penjawab (21.0) dan pekerjaan nelayan sebanyak 55 penjawab (55.0) pekerjaan PNS sebanyak 3 penjawab (3.0) pekerjaan TNI/POLRI sebanyak 1penjawab (1.0) sedangkan pekerjaan wiraswasta sebanyak 20 penjawab (20.0).

\section{d. Pendapatan}

Table 4

Distribusi Freukensi Berdasarkan pendapatan

\begin{tabular}{ccc}
\hline Pendapatan & $\mathrm{N}$ & Persentase (\%) \\
\hline$<1.500 .000,^{-}$ & 70 & $70.0 \%$ \\
$>1.500 .000,^{-}$ & 30 & $30.0 \%$ \\
Total & 100 & 100.0 \\
\hline
\end{tabular}

Sumber: data primer

Berdasarkan table 4 distribusi pendapata $<1.500 .000$, sebanyak 70 penjawab (70.0) dan pendapata > 1.500.000,- sebanyak 30 penjawab (30.0).

\section{e. Partisipasi}

Table 5

Distribusi Freukensi Berdasarkan partisipasi

\begin{tabular}{ccc}
\hline Partisipasi & $\mathrm{n}$ & Persentase (\%) \\
\hline Berpartisipasi & 94 & $94.0 \%$ \\
$\begin{array}{c}\text { tidak } \\
\text { berpartisipasi } \\
\text { Total }\end{array}$ & 6 & $6.0 \%$ \\
\hline
\end{tabular}

Berdasarkan table 5 distribusi berpartisipasi sebanyak 37 penjawab (37.0) dan tidak berpartisipasi sebanyak 63 penjawab (63.0).

\section{f. Pemahaman}

Table 6

Distribusi Freukensi Berdasarkan Pemahaman

\begin{tabular}{|c|c|c|}
\hline Pemahaman & $\mathrm{n}$ & Persentase (\%) \\
\hline Memahami & 31 & 31.0 \\
\hline Tidak Memahami & 69 & 69.0 \\
\hline Total & 100 & 100 \\
\hline
\end{tabular}

\section{g. Penerima Bantuan Iuran}

Table 7

Distribusi Freukensi Berdasarkan Penerima Bantuan Iuran

\begin{tabular}{lcc}
\hline $\begin{array}{l}\text { Penerima bantuan } \\
\text { iuran }\end{array}$ & $\mathbf{n}$ & Persentase (\%) \\
\hline $\begin{array}{l}\text { Memahami } \\
\text { Tidak Memahami }\end{array}$ & 52 & 48.0 \\
& 100 & 100 \\
Total & 52.0 \\
\hline $\begin{array}{l}\text { Berdasarkan table } 7 \text { distribusi memahami sebanyak } 48 \\
\text { penjawab (48.0\%) } \\
\text { penjawab (52.0\%) }\end{array}$
\end{tabular}




\section{B. Hasil Bivariat \\ a. Hubungan Pekerjaan Dengan Pemahaman PBI
BPJS KesehataN}

Table 8

Distribusi Hubungan Pekerjaan Dengan Pemahaman PBI BPJS Kesehatan

\begin{tabular}{llc}
\hline \multirow{2}{*}{ Pekerjaan } & \multicolumn{3}{c}{ Pemahaman } & $P$ \\
\cline { 2 - 3 } & Memahami & $\begin{array}{c}\text { Tidak } \\
\text { memehami }\end{array}$ \\
\cline { 2 - 3 }
\end{tabular}

\begin{tabular}{lcccl} 
Petani & 21 & 1 & 22 & \\
Nelayan & 7 & 47 & 54 & Value \\
PNS & 0 & 3 & 3 & 0.000 \\
TNI/POLRI & 20 & 1 & 1 & \\
Wiraswasta & & 0 & 20 & \\
Total & 48 & 52 & 100 & \\
\hline
\end{tabular}

\begin{tabular}{lrlll} 
Total & 48 & & 52 & 100 \\
\hline Berdasarkan tabel 8 hasil Pengukuran hubungan
\end{tabular} Pekerjaan Dengan tingkat pemahaman penjawab Petani sebanyak 21 penjawab yang memahami sebanyak 20 penjawab (20.0\%) sedangkan penjawab yang tidak memahami sebanyak 1 penjawab $(1.0 \%)$

Pekerjaan Dengan tingkat pemahaman penjawab Nelayan sebanyak 54 penjawab yang memahami sebanyak 7 penjawab (7.0\%) sedangkan penjawab yang tidak memahami sebanyak 47 penjawab (47.0\%).

Pendidikan Dengan tingkat pemahaman penjawab PNS sebanyak 3 penjawab yang memahami tidak ada sedangkan penjawab yang tidak memahami sebanyak 3 penjawab (3.0\%)

Pendidikan Dengan tingkat pemahaman penjawab TNI/POLRI sebanyak 1 penjawab yang memahami tidak ada sedangkan penjawab yang tidak memahami sebanyak 1 penjawab (1.0\%)

Pendidikan Dengan tingkat pemahaman penjawab Wiraswasta sebanyak 20 penjawab yang memahami sebanyak $20(20.0 \%)$ sedangkan penjawab yang tidak memahami tidak ada.

Berdasarkan Uji statistik hubungan Pekerjaan dengan tingkat pemahaman penerimah bantuan iuran BPJS kesehatan menggunakan uji chi square didapatkan nilai $\mathrm{p}=0.000(>0,05)$ maka H0 diterima kemudian ada hubungan bermakna antara Pekerjaan dengan tingkat pemahaman penerimah bantuan iuran BPJS Kesehatan.

\section{b. Hubungan pendapatan Dengan Pemahaman PBI BPJS kesehatan}

Table 9

Distribusi Hubungan Pendapatan Dengan Pemahaman PBI BPJS Kesehtan

\begin{tabular}{lcccc}
\hline Pendapatan & \multicolumn{2}{c}{ Pemahaman } & & \\
& Memahami & Tidak & $\%$ & $P$ \\
$<1.500 .000$ & 48 & 22 & 70 & Value \\
\cline { 2 - 5 }$>$ & 0 & 30 & 30 & 0.000 \\
$1.500 .000,-$ & 48 & 52 & 100 & \\
Total & & & & \\
\hline
\end{tabular}

Berdasarkan tabel 9 hasil Pengukuran hubungan

Pendapatan Dengan tingkat pemahaman penjawab sebanyak 70 dan pendapatan $<1.500 .000,^{-}$yang memahami sebanyak 48 penjawab $(48.0 \%)$ sedangkan penjawab yang tidak memahami sebanyak 22 penjawab $(22.0 \%)$

Pendapatan Dengan tingkat pemahaman penjawab $>1.500 .000$, $^{-}$sebanyak 30 penjawab tidak memahami sebanyak 30 penjawab (7.0\%) sedangkan penjawab yang memahami tidak ada.

Berdasarkan Uji statistik hubungan Pendapatan dengan tingkat pemahaman penerimah bantuan iuran BPJS kesehatan menggunakan uji chi square didapatkan nilai $\mathrm{p}=0.000(>0,05)$ maka HA diterima kemudian ada hubungan bermakna antara Pendapatan dengan tingkat pemahaman penerima bantuan iuran BPJS Kesehatan

\section{c. Hubungan Pekerjaan Dengan Partisipasi PBI BPJS Kesehatan}

Tabel 10

Distribusi Hubungan Pendapatan Dengan Partisipasi PBI BPJS Kesehatan

\begin{tabular}{lcccc}
\hline \multirow{2}{*}{ Pekerjaan } & Partisipasi & & & \\
\cline { 2 - 3 } & Berpartisipasi & $\begin{array}{c}\text { Tidak } \\
\text { Berpartisipasi }\end{array}$ & & $P$ \\
\hline Petani & 14 & 0 & 14 & \\
Nelayan & 5 & 0 & 5 & Value \\
PNS & 9 & 44 & 53 & 0.000 \\
TNI/POLRI & 0 & 1 & 1 & \\
Wiraswasta & 20 & 7 & 27 & \\
Total & 48 & 52 & 100 & \\
& & & &
\end{tabular}

Sumber: Data Primer

Berdasarkan tabel 10 hasil Pengukuran hubungan Pekerjaan dalam berpartisipasi penjawab Petani sebanyak 14 penjawab yang tidak berpartisipasi sebanyak 0 penjawab (0\%) sedangkan penjawab yang tidak memahami sebanyak 1 penjawab (1.0\%),Pekerjaan dalam berpartisipasi penjawab Nelayan sebanyak 5 penjawab yang tidak berpartisipasi sebanyak 0 penjawab (0\%),Pekerjaan dalam berpartisipasi penjawab PNS sebanyak $3(3,0 \%)$ penjawab yang memahami tidak berpartisipasi sebanyak 44 penjawab $(44.0 \%)$, Pekerjaan dalam berpartisipasi penjawab TNI/Polri sebanyak $0 \quad(0 \%)$ penjawab yang tidak berpartisipasi sebanyak 1 penjawab (1\%), Pekerjaan dalam berpartisipasi penjawab Wiraswasta sebanyak $20(20 \%)$ penjawab yang tidak berpartisipasi sebanyak 7 penjawab (7\%). Berdasarkan Uji statistik hubungan Pekerjaan dengan Partisipasi Penerima Bantuan Iuran BPJS kesehatan menggunakan uji chi square didapatkan nilai $\mathrm{p}=0.000$ $(>0,05)$ maka H0 diterima kemudian ada hubungan bermakna antara Pekerjaan dengan Partisipasi penerima bantuan iuran BPJS Kesehatan. 


\section{d. Hubungan pendapatan Dengan Partisipasi PBI BPJS kesehatan}

Table 11

Distribusi pendapatan Dengan Partisipasi PBI BPJS kesehatan

\begin{tabular}{|c|c|c|c|c|}
\hline \multirow[b]{2}{*}{ Pendapatan } & \multicolumn{2}{|l|}{ Partisipasi } & \multirow[b]{2}{*}{$\%$} & \multirow[b]{2}{*}{$P$} \\
\hline & Berpartisipasi & $\begin{array}{c}\text { Tidak } \\
\text { Berpartisipasi }\end{array}$ & & \\
\hline$<1.500 .000,^{-}$ & 0 & 40 & 40 & Value \\
\hline$>1.500 .000,^{-}$ & 45 & 15 & 60 & 0.000 \\
\hline Total & 45 & 55 & 100 & \\
\hline
\end{tabular}

Berdasarkan tabel 11 hasil Pengukuran hubungan Pendapatan penjawab yang berpartisipasi sebanyak 45 $(45 \%)$,pendapatan < 1.500.000,- yang berpartisipasi sebanyak 0 penjawab (0\%) sedangkan pendapatan $>1.500 .000$, $^{-}$yang tidak berpartisipasi sebanyak 0 $(0 \%)$,dan hubungan Pendapatan penjawab yang tidak berpartisipasi sebanyak $55 \quad(55.0 \%)$, pendapatan $>1.500 .000$,- yang berpartisipasi sebanyak 45 penjawab $(45.0 \%)$ sedangkan pendapatan $>1.500 .000,-$ yang berpartisipasi sebanyak $0(0 \%)$,

Pendapatan dengan Partisipasi penjawab $<1.500 .000$, sebanyak 0 penjawab tidak memahami sebanyak 40 penjawab (4.0\%),Pendapatan dengan Partisipasi penjawab $>1.500 .000,-$ sebanyak $45(45 \%)$ penjawab tidak memahami sebanyak 55 penjawab (55.0\%)

Berdasarkan Uji statistik hubungan Pendapatan dengan Partisipasi Penerima Bantuan Iuran BPJS Kesehatan menggunakan uji chi square didapatkan nilai $\mathrm{p}=0.000(>0,05)$ maka HA diterima kemudian ada hubungan bermakna antara Pendapatan dengan Partisipasi penerima bantuan iuran BPJS Kesehatan.

\section{Pembahasan}

\section{Analisis Bivariat}

a. Hubungan pekerjaan dengan pemahaman penerima bantuan iuran BPJS Kesehatan

Berdasarkan uji faktual hubungan Usaha dengan tingkat pemahaman penerima manfaat bantuan komitmen kesejahteraan BPJS dengan menggunakan uji chi square diperoleh nilai $\mathrm{p}=$ 0,000 (> 0,05), kemudian diakui H0 kemudian terdapat hubungan kritis antara Pekerjaan dan tingkat pemahaman penerima bantuan komitmen BPJS Kesejahteraan.

Melinda, Anneke Suparwati, Antono Suryoputro Cakupan Kesehatan Masyarakat ialah unsur yang sah yang dibentuk untuk mengatur programprogram keamanan yang ditentukan untuk memahami pengaturan kebutuhan dasar. BPJS Kesejahteraan fokus bahwa pada tahun 2017 akan lebih dari $90 \%$ penduduk Indonesia yang telah bergabung dengan BPJS Kesejahteraan. Namun, sebenarnya peserta BPJS yang telah mendaftar di
Indonesia sebanyak 179.474.296 orang dengan jumlah 68,53\%. Pencantuman kepesertaan BPJS Kesejahteraan dalam Peraturan Labuhanbatu Selatan ialah 85.816 orang dari 313.884 orang dengan tingkat 27,34\%. Penyelidikan ini diharapkan dapat memutuskan unsur-unsur yang diidentifikasikan dengan local area support dalam kerjasama BPJS Mandiri di ruang fungsi Puskesmas Kotapinang. Penelitian ini menggunakan penelitian studi logika dengan pendekatan cross area. Populasi habis-habisan ialah 28.356 individu yang menggunakan persamaan pengujian arbitrer relatif Notoatmodjo terhadap 100 penjawab. Pemeriksaan informasi menggunakan uji Chi Square, pemeriksaan univariat, dan pemeriksaan bivariat dengan derajat besar $5 \%$ dengan tingkat kesalahan 0,05. Konsekuensi dari pemeriksaan ini ialah $43 \%$ penjawab sebagai peserta BPJS Mandiri. Ada hubungan antara penghindaran bahaya dengan dukungan kelompok masyarakat BPJS Mandiri $(p=0,001)$, ada hubungan antara musibah dan investasi kelompok masyarakat BPJS Mandiri $(p=0,001)$, ada hubungan komitmen dengan kerjasama kelompok masyarakat BPJS Mandiri $(p=0,002)$ dan ada hubungan antara pembayaran dan bunga daerah pada BPJS Mandiri $(p=0,00)$. Masyarakat umum sebagai peserta BPJS Mandiri merasakan banyak keuntungan, sedangkan sebagian besar peserta BPJS Mandiri menyatakan tidak perlu repot dengan BPJS Mandiri. Akhir dari penelitian ini ialah ada hubungan antara penghindaran bahaya, kemalangan habis-habisan, komitmen dan pembayaran dengan kepesertaan BPJS Mandiri wilayah setempat. Berdasarkan hasil pemeriksaan tersebut, disarankan agar BPJS Kesejahteraan membantu perintis daerah setempat untuk memajukan keunggulan BPJS Mandiri dan membicarakannya dengan daerah setempat..

b. Hubungan pendapatan pemahaman penerima bantuan iuran bpsj Kesehatan

Berdasarkan uji coba terukur dari hubungan antara gaji dan tingkat pemahaman penerima manfaat bantuan komitmen kesejahteraan BPJS dengan menggunakan uji chi square, nilai $p=0,000(>0,05)$ menyiratkan bahwa HA diakui kemudian ada nilai kritis hubungan antara gaji dan tingkat pemahaman penerima bantuan komitmen BPJS Kesejahteraan.

Eksplorasi ini sesuai dengan kajian Sri Nurul Kur'aini. Pemeriksaan informasi yang dilakukan ialah univariat dan bivariat dengan menggunakan uji chi square. Hasil uji chi square menunjukkan bahwa terdapat pengaruh variabel gaji $(p=0,016)$ terhadap pendapatan terbuka pada kerjasama BPJS Kesejahteraan di Kelurahan Duampanua Rezim Pinrang. Akhir dari penelitian ini ialah adanya pengaruh faktor pembayaran terhadap iuran individu dalam kerjasama BPJS 
Kesejahteraan di Wilayah Duampanua Rezim Pinrang.

Hasil eksplorasi Riska Nurfadillah R. menunjukkan bahwa faktor-faktor yang mempengaruhi resistensi masyarakat umum membayar BPJS Kesehatan untuk kelas peserta gratis di sub wilayah Sudiang Raya ialah faktor bayaran $(p=0,014)$, kearifan $(p=0,002)$, dan inspirasi $(p=0,012)$. Disarankan kepada BPJS Kesejahteraan untuk lebih mensosialisasikan kepada masyarakat luas tentang pertanggungan Kesehatan Masyarakat yang diidentikkan dengan masalah persetujuan keterlambatan angsuran komitmen BPJS Kesejahteraan.

c. Hubungan partisipasi penerima bantuan iuran bpsj Kesehatan

Dilihat dari uji terukur hubungan kepentingan dan tingkat pemahaman penerima manfaat bantuan komitmen kesejahteraan BPJS dengan menggunakan uji chi square, nilai $\mathrm{p}=0,000(>0,05)$ menyiratkan bahwa HA diakui kemudian terdapat nilai kritis hubungan antara gaji dan tingkat pemahaman penerima bantuan komitmen BPJS Kesejahteraan.

Sedangkan akibat eksplorasi Nyoman Sumawidayani, Ni Wayan Suprilyani, Komang Adi Sastra Wijaya Sesuai hasil uji koefisien penasuransi yang menunjukkan $66,2 \%$, presentasi Badan Pengelola Pembantu Pensiun Federal (BPJS) Pekerjaan di Kota Denpasar terkena imbasnya. oleh dukungan daerah setempat, sedangkan sisanya ialah 33,8\% Kepastian model yang digunakan untuk mendobrak dampak kerjasama daerah pada pameran Badan Pengatur Pensiun Federal (BPJS) Tenaga Kerja Kota Denpasar tergantung pada model pemeriksaan kekambuhan dasar yang diperoleh kondisi tersebut, yakni $\mathrm{Y}=8,484+0,835$ $\mathrm{X}$. Uji langsung relaps dilakukan dengan bantuan program SPSS. 22 cenderung terlihat bahwa untuk setiap kenaikan 1\% kerjasama daerah, presentasi BPJS Pekerjaan di Kota Denpasar akan meningkat sebesar 0,835 .

d. Hubungan pemahaman dengan penerima bantuan iuran BPJS Kesehatan

Berdasarkan Uji statistik hubungan Dilihat dari uji terukur hubungan pemahaman dan tingkat pemahaman penerima bantuan komitmen kesejahteraan BPJS dengan menggunakan uji chi square diperoleh nilai $\mathrm{p}=0,000(>0,05)$ maka, pada saat itu HA ialah diketahui bahwa ada hubungan yang kritis antara gaji dan tingkat pemahaman penerima bantuan komitmen BPJS Kesejahteraan.

Akibat pemeriksaan Viona Febya Pangestika, Sutopo Patria Jati, Ayun Sriatmi mengakui Inklusi Kesejahteraan Meluas 2019, menjadi anggota cakupan pelayanan kesehatan masyarakat tidak hanya dibutuhkan untuk daerah konvensional. Namun, area kasual juga diperlukan untuk mengikuti cakupan layanan Kesehatan Masyarakat.
Di Kota Pekalongan sebagian besar penduduknya bekerja di daerah lepas (pengusaha atau pedagang), namun untuk pencapaian cakupan pelayanan Kesehatan Masyarakat, kerjasama pelaku usaha ialah 14,39\%. Motivasi di balik pemeriksaan ini ialah untuk membedakan dan menyelidiki faktorfaktor yang diidentifikasi dengan kerjasama bidang kasual di BPJS Kesejahteraan Mandiri. Eksplorasi semacam ini bersifat kuantitatif dengan teknik logika, metodologi cross sectional, dan uji utilisasi Chi Square. Ukuran contoh ialah 106 penjawab yang ialah pengusaha/pedagang. Hasil penelitian menunjukkan bahwa sebagian besar penjawab memiliki informasi yang tidak berdaya (50,9\%), jumlah KK 2-4 orang $(88,7 \%)$, gaji di atas gaji terendah yang diizinkan oleh undang-undang $(96,2 \%)$, bulan normal untuk konsumsi sebulan tidak sebanyak bayar $(90,6 \%)$, bayar retribusi $(55,0 \%)$, bisa bayar pengeluaran $(61,3 \%)$, dan dukungan keluarga rendah (70,8\%). Faktor-faktor yang teridentifikasi dengan minat santai di BPJS Kesehatan Mandiri ialah konsumsi normal bulan ke bulan $(p=0,001)$, kesiapan membayar $(p=0,000)$, kemampuan membayar $(\mathrm{p}=0,000)$, dan dukungan keluarga $(p=0,009)$. Sedangkan faktor acak ialah informasi $(p=0,053)$, jumlah kelurahan $(p=0,635)$, dan gaji $(p=0,050)$. Konservatif Keadaan dan dukungan keluarga ialah komponen mendasar dalam kepentingan bidang kasual di BPJS Kesehatan Mandiri. Kelompok masyarakat, khususnya masyarakat biasa, diharapkan memiliki pilihan untuk berperan serta secara efektif dan melaksanakan data tentang BPJS Kesehatan yang diperoleh dengan menabung sebagian dari gajinya untuk menjadi anggota BPJS Kesehatan Mandiri. Untuk sosialisasi BPJS Kesejahteraan kepada lapisan RT, sangat vital sebagai tim dengan kerangka kerja Puskesmas..

\section{SIMPULAN}

Tingkat Pemahaman Masyarakat Dusun Silopo Terhadap Penerima Bantuan Iuran BPJS Kesehatan dapat diambil kesimpulan sebagai berikut;

1. Adanya hubungan variabel Pekerjaan dengan tingkat pemahaman Penerima Bantuan Iuran BPJS Kesehatan dengan nilai Chi Square $p=0,000$ dan standar toleransi 0,05

2. Adanya hubungan variabel Pendapatan dengan tingkat pemahaman Penerima Bantuan Iuran BPJS Kesehatan dengan nilai Chi Square $p=0,000$ dan standar toleransi 0,05

3. Adanya hubungan variabel Pekerjaan dengan Partisipasi Penerima Bantuan Iuran BPJS Kesehatan dengan nilai Chi Square $p=0,000$ dan standar toleransi 0,05

4. Adanya hubungan variabel pendapan dengan Partisipasi Penerima Bantuan Iuran BPJS 
Kesehatan dengan nilai Chi Square $p=0,000$ dan standar toleransi 0,05

\section{DAFTAR PUSTAKA}

Amin, M. (2020). Analisis Perilaku Masyarakat Pedesaan Terhadap Asuransi Kesehatan Nasional Dalam Perspektif Komunikasi Kesehatan. Jurnal Hidup Sehat, 1 (2).

DINAS CAPIL . (2019). Data Catatan Sipil. Polewali: DINAS CAPIL.

Jaya, P. (2017). Kepesertaan Masyarakat Dalam Asuransi Kesehatan Nasional Secara Mandiri. HIGEA, 1 (1).

Kemenkes. (2013). Buku Pegangan Sosialisasi Asuransi Kesehatan Nasiona (JKN) dalam Sistim Asuransi Sosial Nasional. Jakarta: Kementrian Kesehatan RI.

KEMENSOS. (2018). BPJS Kesehatan. Jakarta: Kementrian Sosial.

Mardewi. (2019). Identifikasi Penyebab Rendahnya Kepesertaan Jkn Pada Pekerja Sektor Informal Di Kawasan Pedesaan. Juornal Administrasi Kesehatan, 3 (1).

Marta, H. (2015). BPJS Badan Penyelenggara Asuransi Sosial. Jakarta: KEMENKES.

Martono, N. (2011). Metode Penelitian Kuantitatif. Bandung: Grafindo persada Raya.

Sogiyono. (2017). Metode Penelitian Kuantitatif, Kualitatif, $R \& D$. Jakarta: Gramedia.

Syahrul. (2016). Analisis Faktor faktor Yang Mempengaruhi Partisipasi Dalam Program Asuransi BPJS Kesehatan. Jurnal Kesmas, 2 (1). 